\title{
Highly Photoluminescent Sulphide Clusters Confined in Zeolites
}

A. Ruivo ${ }^{1,2}$, E. Coutino-Gonzalez ${ }^{3,4}$, M. M. Santos ${ }^{1}$, W. Baekelant ${ }^{3}$, E. Fron ${ }^{3}$, M.B.J. Roeffaers $^{5}$, F. Pina ${ }^{1}$, J. Hofkens ${ }^{3}$ and C.A.T. Laia ${ }^{1 *}$

${ }^{1}$ LAQV@REQUIMTE, Chemistry Department, Faculty of Science and Technology, Universidade NOVA de Lisboa, 2829-516 Caparica, Portugal. Tel: + 351212948 300;

${ }^{2}$ Research Unit VICARTE, Vidro e Cerâmica para as Artes, Faculty of Science and Technology, Universidade NOVA de Lisboa, 2829-516 Caparica, Portugal. Tel: +351 212947893;

${ }^{3}$ Chem\&Tech - Molecular Imaging and Photonics, KU Leuven, Celestijnenlaan 200F, B3001 Leuven, Belgium.

${ }^{4}$ CONACYT-Centro de Investigación y Desarrollo Tecnológico en Electroquímica, Parque Industrial Querétaro, Sanfandila s/n, Pedro Escobedo 76703, Querétaro, Mexico. ${ }^{5}$ Chem\&Tech - Centre for Surface Chemistry and Catalysis, KU Leuven, Celestijnenlaan 200F, B-3001 Leuven, Belgium.

* Corresponding author, email: catl@fct.unl.pt and Tel: + 351 212948310; Fax: +351212948550 


\begin{abstract}
The design, synthesis and photoluminescence characterization of sulphide cluster-based zeolitic materials with the general formula $\mathrm{Na}_{8}\left[\mathrm{SiAlO}_{4}\right]_{6} \mathrm{~S}_{\mathrm{x}} \mathrm{Cl}_{2-2 \mathrm{x}}$ is presented in this report. The employed experimental conditions, which included the thermal treatment of sodium Linde type A (Na-LTA) zeolites, yielded highly photoluminescent sulphurzeolites and remarkably large Stokes shifts. An emission band at $650 \mathrm{~nm}$ for samples with low sulphur contents is observed when excited at $380 \mathrm{~nm}$, which is fully consistent with $\mathrm{S}_{2}{ }^{-}$clusters as light emitting centres. These orange emitting materials display External Quantum Efficiencies reaching 53\% with peculiar high temperature stability of photoluminescence up to $450^{\circ} \mathrm{C}$. For higher $\mathrm{S} / \mathrm{Cl}$ molar ratios a gradual conversion to Near-Infrared (NIR) light emitting centres is observed with a maximum at $780 \mathrm{~nm}$. This novel NIR luminescent species with External Quantum Efficiencies of about $10 \%$ are attributed to polysulfide clusters (tentatively $\mathrm{S}_{4}{ }^{2-}$ species). Giving the high EQE values, large Stokes shifts, and thermal stability, the materials presented in this report can find applications in light down-conversion systems or as phosphors in lighting devices.
\end{abstract}




\section{INTRODUCTION}

Luminescent materials are part of our daily life, having numerous technological applications, such as in biomedical imaging, lasers and lighting devices. ${ }^{1-3}$ These devices can employ organic compounds that show the necessary brightness and that can be tuned to obtain an acceptable colour range, yet they are prone to suffer degradation thus limiting their applications. ${ }^{4,5}$ Inorganic materials such as phosphors and quantum dots are also used to produce Light Emitting Diodes (LEDs) and fluorescent lamps with the advantage of being less prone to degradation processes. However, their production frequently requires the use of toxic elements or scarce and expensive raw materials, viz. rare earth oxides, ${ }^{6,7}$ indium, ruthenium or iridium. ${ }^{8-10}$ Other materials may overcome some of these potential disadvantages, using inexpensive and non-toxic raw materials while keeping the typical performances of commercial phosphors.

Potential alternative hosts are nanoporous materials such as zeolites, which are remarkably suited to enclose lanthanide ions ${ }^{11}$ or produce entrapped photoluminescent nanoclusters, e.g. with silver or silicon. ${ }^{12-15}$ In the specific case of silver-cluster zeolite composites, optimized synthetic procedures allow the tuning of their emission properties within the visible spectra with very high UV to visible conversion efficiencies (external quantum efficiencies up to $97 \%) .{ }^{16,17}$ Besides the abovementioned elements other metals, such as copper, bismuth and lead, have also been embedded in different zeolitic structures conferring them photoluminescent properties. ${ }^{18-20}$ It is also known that sulphur and chloride anions can be entrapped in zeolites with sodalite cage-containing topologies. ${ }^{21}$ Hackmanite mineral is a natural occurring sodalite-based crystalline structure with the general stoichiometry $\mathrm{Na}_{8}\left[\mathrm{SiAlO}_{4}\right]_{6} \mathrm{Cl}_{2}$, which displays natural photochromic and/or photoluminescent properties due to sulphur doping. ${ }^{22}$ The photochromic effect has been linked to $\mathrm{S}_{2}{ }^{2-}$, where a deep pink or violet colour appears after exposure to UV-C 
radiation, generating an isolated caged electron, reverting to the uncoloured state after exposition to visible light. ${ }^{21}$ The rich sulphur chemistry may also generate entrapped $\mathrm{S}_{3}{ }^{-}$ anions responsible for the well-known blue colour pigments (ultramarine blue) ${ }^{23}$ or entrapped $\mathrm{S}_{2}{ }^{-}$anions which give rise to orange photoluminescence. ${ }^{24}$ In both cases the sulphur species are free radicals stabilized by lattice entrapment. ${ }^{25}$ In sodalite-based crystalline phases this effect is rather general within the chalcogen group intercalating not only sulphur, ${ }^{26}$ but also other chalcogens such as selenium and tellurium species conferring different optical properties to the synthesized materials. ${ }^{21,27}$

Although the numerous possibilities of these sulphur-zeolite composites are recognized, systematic controlled synthetic routes are still scarce, and information about their luminescence quantum yields is still lacking, hampering their proper evaluation and potential use in photonics or photoluminescence applications.

The work reported here is motivated by these criteria. The use of solid-state reaction routes allows obtaining sodium aluminosilicates, such as sodalite crystalline structures, encapsulating different anionic species. These sodalite zeolites consist of $\mathrm{SiO}_{4}{ }^{4-}$ and $\mathrm{AlO}_{4}{ }^{5-}$ tetrahedra that give rise to four and six-membered rings, which form $\beta$ cages that are also called sodalite cages, which can also be found in Linde type A (LTA) zeolites. There is thus a high resemblance between LTA and sodalite type zeolites, in fact, phase transformation from Na-LTA to sodalite zeolites has been demonstrated at high temperatures around $850{ }^{\circ} \mathrm{C} . .^{21,26,28}$ In this study we present an alternative and costeffective procedure to obtain photoluminescent materials containing sulphur clusters as emissive species. These materials can be synthesized by heating $\mathrm{Na}-\mathrm{LTA}, \mathrm{NaSO}_{4}$ and $\mathrm{NaCl}$, at $900{ }^{\circ} \mathrm{C}$ under a reductive atmosphere $\left(5 \% \mathrm{H}_{2} / 95 \% \mathrm{Ar}, \mathrm{v} / \mathrm{v}\right)$. In such conditions the $\mathrm{SO}_{4}{ }^{2-}$ anionic tetrahedra is reduced to $\mathrm{S}_{2}^{-}$anionic clusters, which display photoluminescent properties. ${ }^{24}$ 
Several techniques were used to characterize the synthesized materials. X-ray diffraction (XRD) and microenergy dispersive X-ray fluorescence ( $\mu$-EDXRF) techniques indicated the presence of two different sodium aluminosilicate crystalline phases after calcination, sodalite and nepheline, and revealed the presence of sulphur and chloride species, which both are dependent on sulphur/chloride $(\mathrm{S} / \mathrm{Cl})$ ratios. Spectroscopic techniques were used to study the optical properties of the photoluminescent materials, which display a broad emission band centred at $650 \mathrm{~nm}$ when excited at $380 \mathrm{~nm}$ and a well-defined vibronic structure consistent with $\mathrm{S}_{2}{ }^{-}$clusters when low sulphur loadings were employed. For high sulphur concentrations, another emission band was observed around $780 \mathrm{~nm}$ with excitation maximum at $345 \mathrm{~nm}$. This luminescence is most probably originating from polysulphides $\mathrm{S}_{4}{ }^{2-}$ species. These materials display high EQE values (up to $53 \%$ ), depending on the sulphur/chloride ratio, and also exhibit extremely high Stokes shifts ( $c a$. $250 \mathrm{~nm}$ across the visible region) making them promising phosphors candidates in lighting devices using inexpensive raw materials.

\section{EXPERIMENTAL DETAILS}

\subsection{Samples preparation.}

Sodium aluminosilicates containing sulphur and chloride anions according to the stoichiometry $\mathrm{Na}_{8}\left[\mathrm{SiAlO}_{4}\right]_{6} \mathrm{~S}_{\mathrm{x}} \mathrm{Cl}_{2-2 \mathrm{x}}$ were prepared via solid state synthesis using an adapted procedure reported for the production of photochromic sodalite zeolites ${ }^{21,26}$ (see Scheme 1). Appropriate amounts of zeolite Na-LTA (Sigma Aldrich) previously dried at $500{ }^{\circ} \mathrm{C}$ for $5 \mathrm{~h}, \mathrm{Na}_{2} \mathrm{SO}_{4}$ (Carlo Erba) and $\mathrm{NaCl}$ (Panreac) corresponding to the following stoichiometry, $\mathrm{Na}_{8}\left[\mathrm{SiAlO}_{4}\right]_{6} \mathrm{~S}_{\mathrm{x}} \mathrm{Cl}_{2-2 \mathrm{x}} \mathrm{x}=0,0.1,0.2,0.3,0.4,0.5,0.6,0.7,0.8$ and 0.9 , were mixed, ball-milled for 1 hour and finally homogenized in a shaker powder mixer for 3 
hours. This stoichiometry corresponds to nominal molar ratios of $\mathrm{S} / \mathrm{Cl}=0,0.06,0.13$, $0.21,0.33,0.50,0.75,1.17,2.0$ and 4.5 , respectively. The obtained powder was sintered in alumina boat crucibles in a horizontal tubular electric furnace (TH1300, Termolab) for 1h at $900{ }^{\circ} \mathrm{C}$ under a reductive atmosphere of $5 \% \mathrm{H}_{2} / 95 \% \mathrm{Ar}(\mathrm{v} / \mathrm{v})$ at $500 \mathrm{~mL} / \mathrm{min}$. Subsequently the quartz tube that provided the reductive atmosphere to the tubular furnace was removed and the material was cooled down to $550{ }^{\circ} \mathrm{C}$ inside the furnace and then quenched to room temperature.

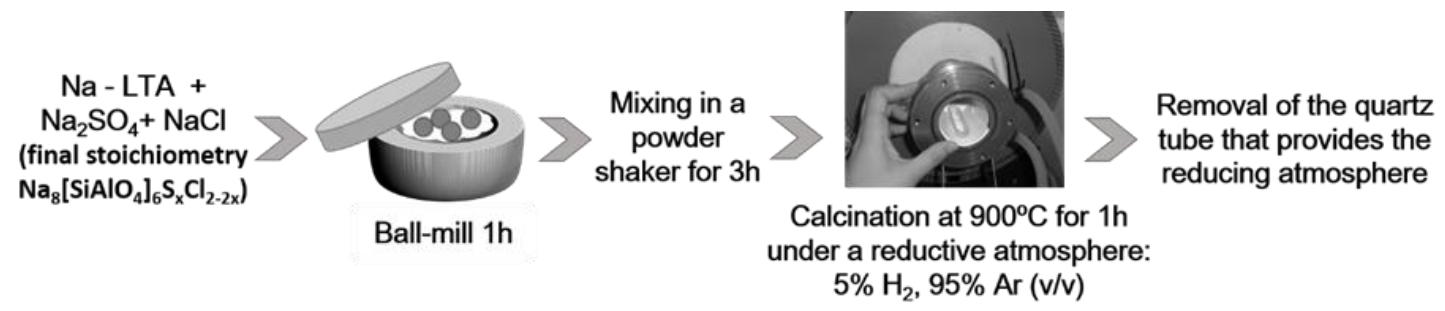

Scheme 1. Schematic diagram of the sodalite zeolite synthesis containing sulphur and chloride anions.

\subsection{Samples characterization}

X-Ray Diffraction experiments. A X-Ray Diffractometer RIGAKU, model MiniFlex II with $\mathrm{Cu}$ X-ray tube $(30 \mathrm{KV} / 15 \mathrm{~mA})$ was used, over a $2 \theta$ range of $10^{\circ}$ to $70^{\circ}$ with a scanning speed of $2 \% \mathrm{~min}$.

Diffuse reflectance. Diffuse reflectance measurements were performed in a Shimadzu UV-2501PC using $\mathrm{BaSO}_{4}$ as a reference sample over the $250-800 \mathrm{~nm}$ wavelength range. Steady-state luminescence. For the emission-excitation characterization, the photoluminescent sulphur-zeolite samples were placed in a quartz cuvette $(1 \mathrm{~mm}$ path length) and sealed by a Teflon stopper. Emission and excitation spectra were recorded using an Edinburgh Instruments FLS 980 fluorimeter. For every excitation wavelength, the emission was collected starting $30 \mathrm{~nm}$ above the excitation wavelength up to $800 \mathrm{~nm}$ using $5 \mathrm{~nm}$ step size for the excitation wavelength. The signal above $410 \mathrm{~nm}$ was 
measured using a $400 \mathrm{~nm}$ long pass glass filter to avoid interference from second-order excitation peaks, the measured intensities were corrected for the transmittance of the long pass filter. The emission was collected in "front face mode" through the quartz cuvette and sent to a PMT for detection. From the separate emission spectra at varying excitation wavelengths, the two and three-dimensional excitation- emission matrices were constructed; the raw data were corrected for background and noise and then interpolated to a resolution of $1 \mathrm{~nm} \times 1 \mathrm{~nm}$. Absolute external quantum efficiencies were measured using an integrating sphere (Labsphere, $100 \mathrm{~mm}$ diameter) coupled to a Horiba Jobin Yvon fluorolog FL3-22 fluorimeter. A commercial phosphor (blue emitting phosphor, $\left.\mathrm{BaMgAl}_{10} \mathrm{O}_{19}: \mathrm{Eu}^{2+}\right)$ with known EQE was measured and used as reference for the calibration of the setup. ${ }^{17}$

Microenergy Dispersive X-ray Fluorescence $(\mu$-EDXRF). X-ray fluorescence spectra were obtained with a portable $\mu$-EDXRF spectrometer ArtTAX 800 of Intax GmbH. The spectrometer is equipped with a molybdenum target $\mathrm{X}$ - ray tube and an electro-thermally cooled silicon drift detector. The system is coupled to a colour CCD camera that provides a magnified digital image of the probed area. The primary X-ray beam diameter is approximately $70 \mathrm{~nm}$ and is focused by means of polycapillary X-ray optics. Spectra were acquired under the following conditions: voltage $40 \mathrm{kV}$, intensity $600 \mu \mathrm{A}$ and $360 \mathrm{~s}$ of live time. For light element analysis, including aluminium, a helium purging system was used.

Raman Microscopy. Raman microspectroscopy was carried out using a Labram 300 Jobin Yvon spectrometer, equipped with a HeNe laser. Each spectrum was collected using $632.8 \mathrm{~nm}$ excitation, a 50x objective and $0.35 \mathrm{~mW}$ laser power.

Fluorescence Microscopy. Fluorescence microscopy images were obtained with an Axioplan 2ie Zeiss imaging microscope equipped with a NikonDXM1200F digital 
camera. Excitation light for fluorescence imaging was selected using a band pass filter of $395-440 \mathrm{~nm}$.

\section{RESULTS AND DISCUSSION}

Several sulphur-zeolites with characteristic photoluminescent properties were obtained using the synthetic protocol described in the Experimental Section. Heating the Na-LTA zeolites at $900{ }^{\circ} \mathrm{C}$ for one hour under a reductive atmosphere of $5 \% \mathrm{H}_{2} / 95 \%$ Ar, in the presence of $\mathrm{Na}_{2} \mathrm{SO}_{4}$ and $\mathrm{NaCl}$, enables the conversion of this zeolite to a sodalite crystalline phase with entrapped $\mathrm{S}_{2}{ }^{-}$species, forming highly photoluminescent sulphurzeolite composites. The reductive atmosphere given by the presence of $\mathrm{H}_{2}$ was essential for the reduction of $\mathrm{SO}_{4}{ }^{2-}$ to $\mathrm{S}_{2}{ }^{-}$species at $900{ }^{\circ} \mathrm{C}$. The synthesis of these compounds is highly sensitive to the process conditions, for example without the reductive atmosphere no coloured or photoluminescent composites are obtained (indicating the absence of redox reaction) but the use of an excess of $\mathrm{H}_{2}$ and longer heating times (more than 1 hour) leads to photochromic pigments due to further reduction to $\mathrm{S}_{2}{ }^{2-}$ species (see Fig. SI-1 of the Supplementary Information).

\subsection{Diffuse reflectance spectroscopy}

Since the materials are opaque powders, light absorption was studied in Diffuse Reflectance mode using the Kubelka-Munk (K-M) theory of diffuse reflection at scattering surfaces to analyse these spectra (Fig. 1). ${ }^{29}$ 

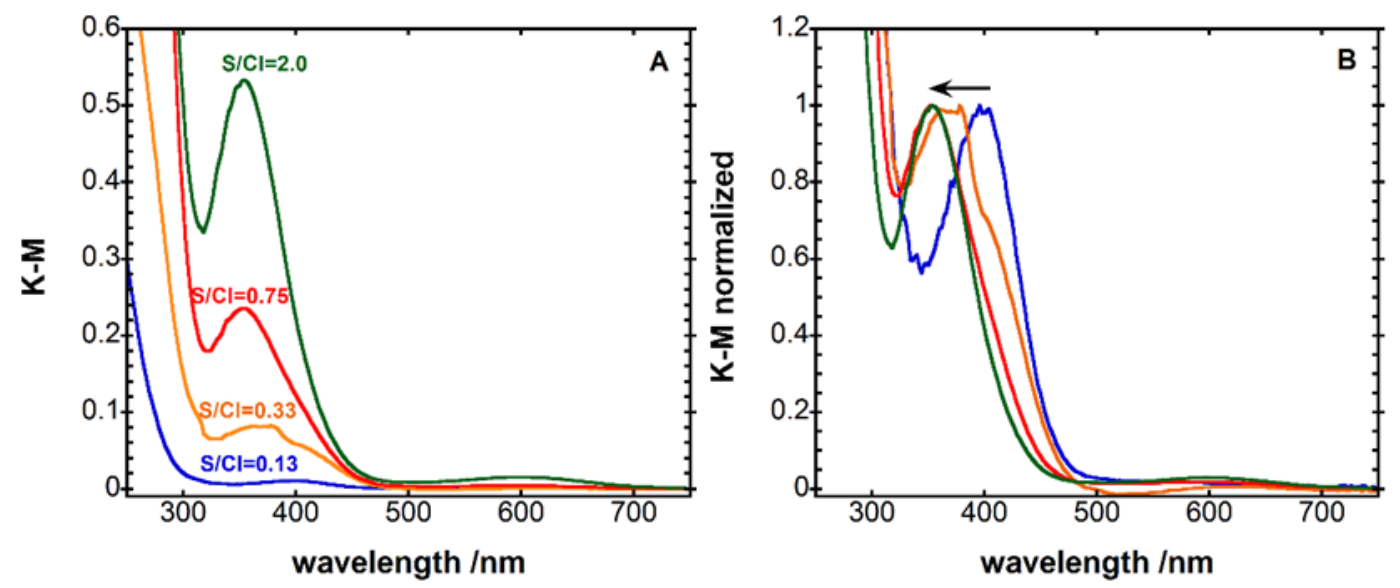

Fig. 1. (A) Diffuse reflectance spectra of samples with nominal molar ratios of $\mathrm{S} / \mathrm{Cl}=0.13,0.33$, 0.75 and 2.0. (B) Diffuse reflectance spectra of the same samples normalized at the maximum of the absorption band in the 300-500 $\mathrm{nm}$ region.

The spectrum of the sample containing a $\mathrm{S} / \mathrm{Cl}$ molar ratio of 0.13 (see Fig. 1) presents a band centred at $400 \mathrm{~nm}$, which is consistent with the ${ }^{2} \Pi_{\mathrm{g}} \rightarrow^{2} \Pi_{\mathrm{u}}$ electronic transition of $\mathrm{S}_{2}{ }^{-}$species. ${ }^{27}$ When the $\mathrm{S} / \mathrm{Cl}$ molar ratio is increased, $\mathrm{S} / \mathrm{Cl} \geq 0.21$, this band gradually shifts to a band centred at about $350 \mathrm{~nm}$ with increasing intensity. This band is in accordance with reported values, both experimental and theoretical, of a polysulfide cluster (a possible cluster is $\mathrm{S}_{4}{ }^{2-}$ ). ${ }^{30}$ In addition, a very low intensity absorbance peak appears at about $600 \mathrm{~nm}$ for higher $\mathrm{S} / \mathrm{Cl}$ ratios $(\geq 0.75)$, being more evident for sample $\mathrm{S} / \mathrm{Cl}=2.0$, see Fig. $1 \mathrm{~A}$. This band is characteristic of $\mathrm{S}_{3}{ }^{-}$species well known from blue ultramarine pigments. ${ }^{27}$ These results confirm the presence of other polysulfide clusters, besides $\mathrm{S}_{2}^{-}$, for samples with higher sulphur contents. Therefore, polysulfide clusters of the type $\mathrm{S}_{\mathrm{n}}{ }^{2-}$ or $\mathrm{S}_{\mathrm{n}}{ }^{-}$are clearly formed for samples with molar ratios $\mathrm{S} / \mathrm{Cl} \geq 0.21$, which may be enhanced by the formation of a different crystalline phase. This issue will be further discussed in the following sections.

For all absorption spectra the features in the region $300-500 \mathrm{~nm}$ could be deconvoluted as two different contributions, absorbing at 350 and $400 \mathrm{~nm}$, of the boundary cases 
obtained at S/Cl molar ratios between 0.13 and 4.5 (see Fig. SI-2 of the Supplementary Information), therefore, all spectra are linear combinations of the two spectra, i.e.:

$K-M=A\left[K-M_{\mathrm{S} / \mathrm{Cl}=0.13}^{\text {norm }} \times y_{A}+K-M_{\mathrm{S} / \mathrm{Cl}=4.5}^{\text {norm }} \times y_{B}\right]$

Where $A$ is the amplitude of the spectra, $K-M^{\text {norm }}$ are the normalized spectra of the samples containing $\mathrm{S} / \mathrm{Cl}$ molar ratios of 0.13 and 4.5 , and $y_{A, B}$ is the fractional contribution of each spectral component for the overall spectra. The $y_{A, B}$ has a sigmoidal dependence with the nominal $\mathrm{S} / \mathrm{Cl}$ ratio and a half-value between 0.33 and 0.50 (around 0.35 ). This is in qualitative agreement with the dimerization process $2 S_{2}^{-} \rightleftharpoons S_{4}^{2-}$, which keeps the overall sulphur oxidation state of the system. Such process has a strong impact in the photoluminescence properties of these materials, as described below.

\subsection{Photoluminescence characterization}

Under a $366 \mathrm{~nm}$ UV lamp the synthesized samples revealed different photoluminescent colours. The sample without sulphur $(\mathrm{S} / \mathrm{Cl}=0)$ does not show visible photoluminescence (see Fig. SI-3 of the Supplementary Information), increasing the sulphur content to $\mathrm{S} / \mathrm{Cl}=0.21$ led to an increase of the orange photoluminescence intensity with chromaticity coordinates $\mathrm{x}=0.57$ and $\mathrm{y}=0.41$. For sulphur-to-chlorine ratios $\mathrm{S} / \mathrm{Cl} \geq 0.5$, the photoluminescence progressively red-shifts with an overall decrease of the emission intensity (see Fig. 2). In this case the chromaticity coordinates are $x=0.53$ and $y=0.33$ when $\mathrm{S} / \mathrm{Cl}=4.5$, consistent with the formation of other emitting species.

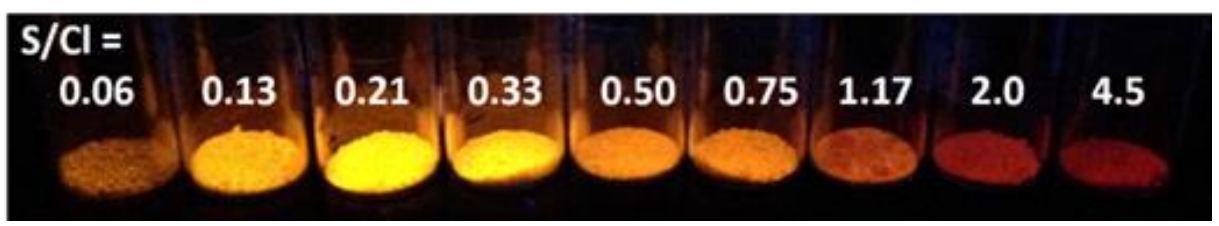

Fig. 2. Photoluminescent sulphur-zeolites corresponding to nominal molar ratios of $\mathrm{S} / \mathrm{Cl}=0.06$, $0.13,0.21,0.33,0.50,0.75,1.17,2.0$ and 4.5 , under $366 \mathrm{~nm}$ illumination. 
The obtained samples were divided in two groups according to the displayed photoluminescence properties: 1) samples with $\mathrm{S} / \mathrm{Cl} \leq 0.33$, displaying an orange emission and an intensity increase with the $\mathrm{S} / \mathrm{Cl}$ molar ratio, and 2) samples having $\mathrm{S} / \mathrm{Cl}$ $\geq 0.50$ which display a shift of the emission spectra into the red/near-infrared (NIR) region with overall decrease of intensity with increasing sulphur content. Samples of group 1 (Fig. $3 \mathrm{~A}, \mathrm{~B}$ ) give rise to a singular broad emission band centred at $650 \mathrm{~nm}$, when excited at $380 \mathrm{~nm}$. The photoluminescence spectra of these samples exhibit a very large Stokes shift and a clear vibronic fine-structure, which is well defined even at room temperature (Fig. 3 A). The separation of the vibronic peaks at $77 \mathrm{~K}, \mathrm{ca} .546 \mathrm{~cm}^{-1}$, is in agreement with the assignment of the emitting species to $\mathrm{S}_{2}^{-}$. Fitting of the data obtained at room temperature with Gaussian functions gives essentially the same result albeit with broader vibronic bands (Fig. SI-4). ${ }^{27}$ This electronic transition has been attributed to ${ }^{2} \Pi_{\mathrm{g}} \rightarrow^{2} \Pi_{\mathrm{u}}$ of $\mathrm{S}_{2}{ }^{-}$clusters embedded in zeolites. ${ }^{31}$ The excitation spectra of group 1 samples overlaps with the absorption spectra, again indicating the origin of the emission to a single species confined in the cavities of the sulphur-zeolite materials.

The samples of group 2, having $\mathrm{S} / \mathrm{Cl}$ ratios higher than 0.33 , are characterized by the appearance of a photoluminescence spectra centred at about $780 \mathrm{~nm}$ (see Fig. 3 C, D and SI-5), where no fine-structures are observed. Most of this emission, which becomes dominant for samples with high sulphur contents $(\mathrm{S} / \mathrm{Cl}$ ratios $\geq 1.17)$, is already in the NIR region, which implies an apparent decrease of photoluminescent intensity to the human eye. This feature also correlates with the absorption spectra, suggesting the formation of a second sulphide cluster, with photoluminescence at $780 \mathrm{~nm}$, probably $\mathrm{S}_{4}{ }^{2-}$, since $\mathrm{S}_{3}{ }^{-}$species (ultramarine blue) also observed in the absorption spectra do not present any luminescence. 

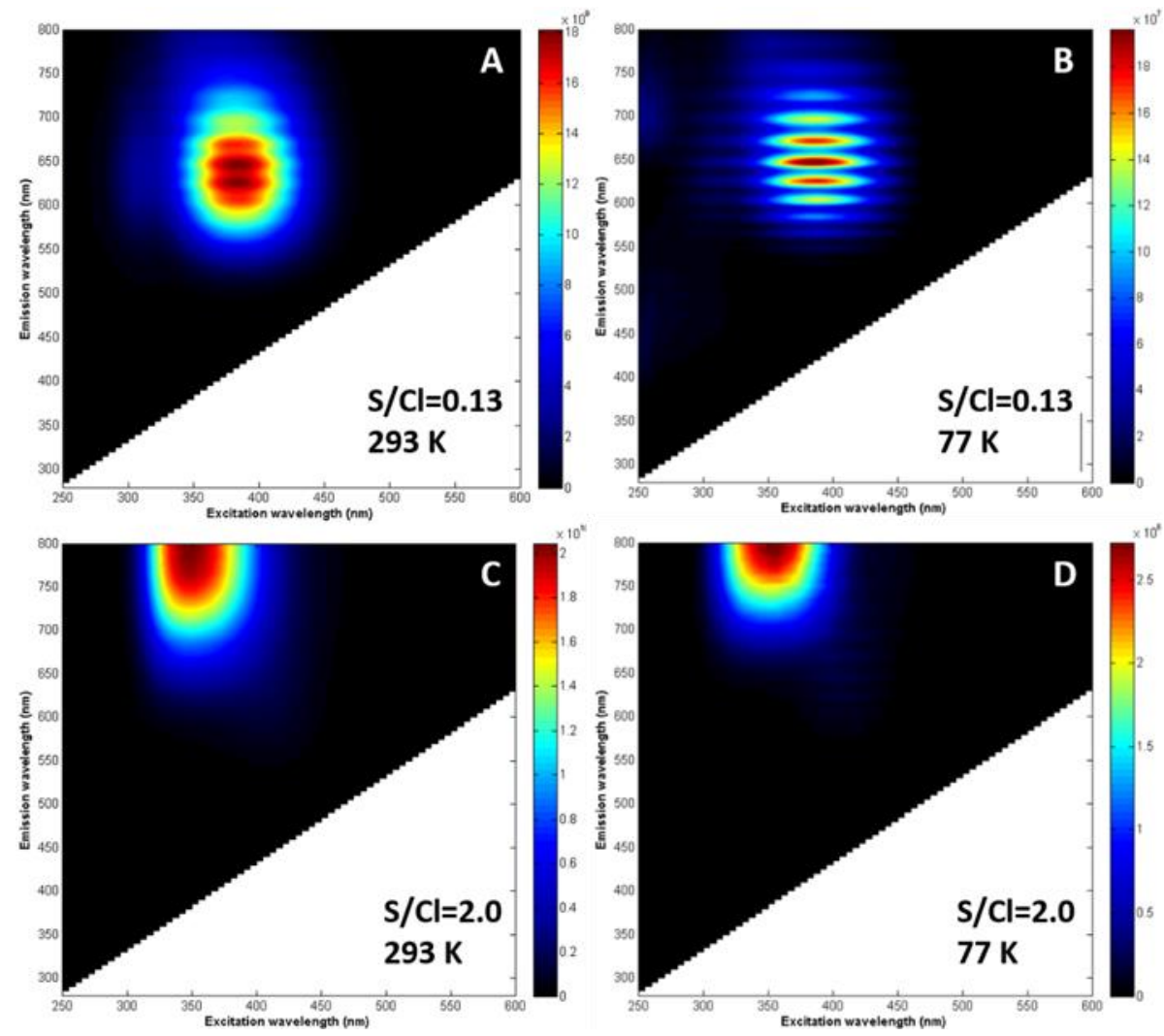

Fig. 3. Two dimensional excitation-emission profiles of photoluminescent sulphur-zeolites doped with $\mathrm{S} / \mathrm{Cl}=0.13$ and 2.0 , at 77 and $293 \mathrm{~K}$.

Fluorescence microscopy images, presented as supplementary material (Fig. SI-6) also show the coexistence of orange and red emission centres. Sample $\mathrm{S} / \mathrm{Cl}=0.50$, for example, present particles with both luminescent colours, which implies a heterogeneous distribution of different emissive sulphur clusters in this sample. Orange emission is prevalent at the nominal molar ratio $\mathrm{S} / \mathrm{Cl}=0.13$, whereas at $\mathrm{S} / \mathrm{Cl}=4.5$, particles exhibiting red photoluminescence become dominant, as was also observed in the respective bulk two-dimensional excitation-emission profiles (Fig. SI-5 and SI-6). At $\mathrm{S} / \mathrm{Cl}=0.50$ there is clearly a mixture of both cases.

The "two-species" hypothesis is consistent when the emission spectra are normalized by the overall emission area (i.e., the area under the curve of each emission spectrum in Fig. $4 \mathrm{~A}$ is normalized to 1 ). For samples $\mathrm{S} / \mathrm{Cl} \geq 0.5$ the relative intensity of the $650 \mathrm{~nm}$ 
emission band decreases while the emission at $780 \mathrm{~nm}$ increases with the $\mathrm{S} / \mathrm{Cl}$ ratio (Fig. 4). Taking into account two different wavelengths where only one of the species emits (550 $\mathrm{nm}$ for orange emitting species and $850 \mathrm{~nm}$ for red/NIR emitting species), it is possible to represent normalized variations of the contribution of the two species for the emission spectra (such relative fractions are depicted in Fig. 4B). At lower S/Cl ratios, the vibronical orange emission, which is the signature of $\mathrm{S}_{2}{ }^{-}$species, is prevalent as it was already observed in the diffuse reflectance measurements (see above). At higher $\mathrm{S} / \mathrm{Cl}$ ratios, the red/NIR emission intensity increases with sulphur concentration (Fig. SI-7) while this emission is absent in the materials of group 1. This dependence on sulphur presence points out that this emission is due to the formation of polysulphides also seen in the absorption spectra. The excitation peak is $350 \mathrm{~nm}$, which shows a coherence between the two data sets. A sigmoidal type fractional dependence is observed with a midpoint at $\mathrm{S} / \mathrm{Cl}=0.75$. A discrepancy is observed between this midpoint, $\mathrm{S} / \mathrm{Cl}=0.75$, and the one obtain in the diffuse reflectance analysis, $\mathrm{S} / \mathrm{Cl}=0.35$. This can be justified by the fact that the two emissive species have different external quantum efficiency values, which are going to be discussed afterwards.

The results also shows that by playing with initial $\mathrm{Na}_{2} \mathrm{SO}_{4}$ amounts, it is possible to tune the luminescent properties either to "orange emitting" or "NIR emitting" materials, which makes them particularly versatile in the design of photoluminescent zeolites in the red region of the spectra. 

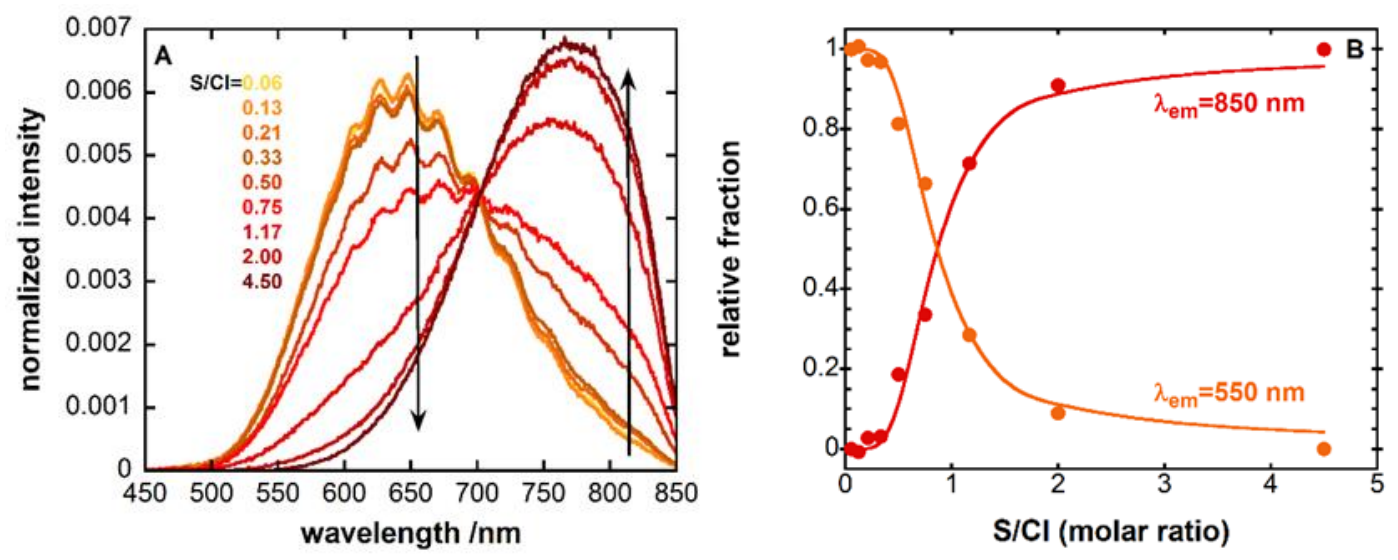

Fig. 4. (A) Photoluminescence spectra, normalized by area (see text above), of sulphur-zeolites corresponding to a nominal molar ratio of $\mathrm{S} / \mathrm{Cl}=0.06,0.13,0.21,0.33,0.50,0.75,1.17,2.0$ and $4.5, \lambda_{\mathrm{exc}}=380 \mathrm{~nm}$. (B) Relative fraction of the emission intensity at $\lambda_{\mathrm{em}}=550 \mathrm{~nm}$ and $850 \mathrm{~nm}$, where only one of the species emits, $\lambda_{\mathrm{exc}}=380 \mathrm{~nm}$.

\subsection{Role of zeolite phase transformation in the luminescence properties}

To study the structure of the zeolite that confine the two-emitting species and how it influences their formation, a characterization was performed using powder X-ray Diffraction (XRD) and Raman spectroscopy. X-ray Fluorescence (XRF) spectroscopy was also employed to analyse the amount of sulphur and chloride that was intercalated in the samples.

The crystalline structure of the samples upon heating was studied by XRD. The XRD pattern of the commercial Na-LTA zeolite used in this report and the pattern corresponding to the synthesized sample with $\mathrm{S} / \mathrm{Cl}=0$ are presented as supplementary material (fig. SI-7), and the remaining are depicted in Fig. 5.

The XRD patterns of the samples in the range between $\mathrm{S} / \mathrm{Cl}=0$ to 0.21 are consistent with the sodalite crystalline phase corresponding to $\mathrm{Na}_{8}\left[\mathrm{SiAlO}_{4}\right]_{6} \mathrm{Cl}_{2}$ (ICDD card 37 0476). Hence, the mixture of sulphur and chloride anions with the Na-LTA zeolite at high temperature and under a reductive atmosphere gave rise to a sodalite zeolite structure. The sodalite and Na-LTA zeolites display very similar structures, as depicted in Scheme 2. Both consist of similar 3D arrangements of tetrahedral $\mathrm{SiO}_{4}$ and $\mathrm{AlO}_{4}$ structures which 
form a $\beta$ cage, also called sodalite cage. ${ }^{32}$ In the sodalite zeolite structure the sodium atoms are coordinated to 3 oxygen atoms of the six-membered rings, and they are available to interact with anionic species. ${ }^{33}$ Chang and co-workers have already reported that the occupation of the cavities of LTA zeolites with ions such as sodium and ionic halogens, when submitted to a heating process, induces the transformation of the initial structure to a sodalite zeolite topology. In this transformation a rotation of the tetrahedral structure occurs, so that $\mathrm{Na}^{+}$is coordinated to the oxygen ions of the zeolite framework and with other anions, such as chlorides. ${ }^{28,34}$ Sodalite crystalline phase is present in samples displaying the vibronical orange emission assigned to $\mathrm{S}_{2}^{-}$species.

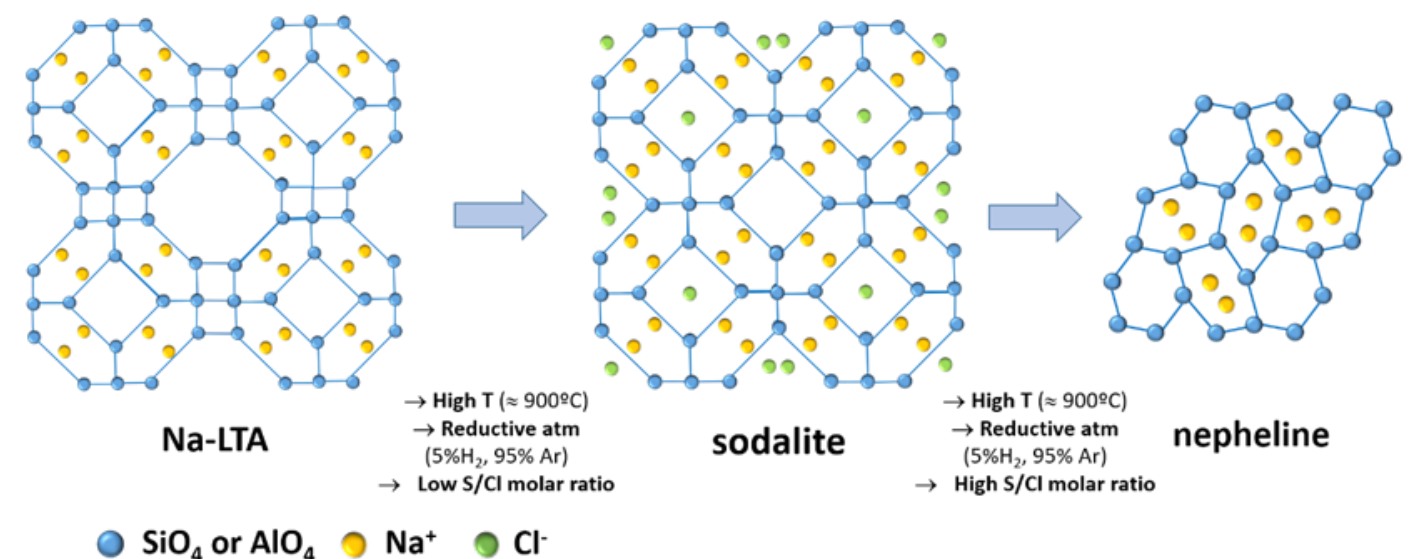

Scheme 1. 2D schematic representation of the sequential conversion from zeolite LTA to sodalite and to nepheline topology.

The high mobility of $\mathrm{Na}^{+}$ions present in the zeolite LTA cavities facilitates the phase conversion of the zeolite. One widely reported example is the transformation of LTA into hydroxysodalite in hydrothermal systems,${ }^{35-37}$ however in the present study we employed a solid state methodology at high temperature $\left(900{ }^{\circ} \mathrm{C}\right)$ in which a sodalite zeolite structure is formed when zeolite LTA is heat-treated according to the following reaction (a): 38 


$$
\underset{\text { Na-LTA }}{\mathrm{Na}_{12} \mathrm{Al}_{12} \mathrm{Si}_{12} \mathrm{O}_{48}}+4 \mathrm{NaCl} \rightarrow \underset{\text { Sodalite }}{2 \mathrm{Na}_{8} \mathrm{Al}_{6} \mathrm{Si}_{6} \mathrm{O}_{24} \mathrm{Cl}_{2}}
$$

By increasing the $\mathrm{S} / \mathrm{Cl}$ molar ratio, more specifically for the samples with $\mathrm{S} / \mathrm{Cl}>0.21$, another crystalline phase appears in the XRD patterns besides sodalite, namely a nepheline phase, $\mathrm{Na}\left[\mathrm{SiAlO}_{4}\right]$ (ICDD card 35-0424). In fact, for the samples with $\mathrm{S} / \mathrm{Cl} \geq$ 2.0 this topology becomes the dominant crystalline phase (see Fig. 5), where the atomic elements form a compact hexagonal arrangement with six-membered hexagonal and oval rings, as depicted in Scheme 2. Consequently, the conversion between such crystalline structures can be easily achieved at the synthesis conditions utilized in this study, as reported by Dimitrijevic and collaborators. ${ }^{39}$ In addition, the nepheline and sodalite crystalline phases are related by the following reversible reaction (b): $:^{33,40,41}$

$$
\begin{aligned}
& 6 \mathrm{NaAlSiO}_{4}+2 \mathrm{NaCl} \leftrightarrows \mathrm{Na}_{8} \mathrm{Al}_{6} \mathrm{Si}_{6} \mathrm{O}_{24} \mathrm{Cl}_{2} \\
& \text { Nepheline } \\
& \text { Sodalite }
\end{aligned}
$$

Hence, the Na-LTA transformation to nepheline phase, when high sulphur contents are employed can occur (i) directly from Na-LTA, ${ }^{39,42}$ or (ii) with sodalite as an intermediate phase. In order to better understand this transformation we have carried XRD experiments using different heating times during the thermal treatment of the sample containing an $\mathrm{S} / \mathrm{Cl}$ nominal molar ratio of 2.0, where the nepheline phase is intensely present (XRD patterns are presented as supplementary material SI-8). On one hand, when the starting material is treated at $900{ }^{\circ} \mathrm{C}$ for 30 minutes, only the peaks corresponding to the sodalite and nepheline phases were identified without the presence of Na-LTA zeolite phases. On the other hand, longer heating times favoured the formation of the nepheline phase, showing that for the samples of group 2 a shorter heating time can be applied to decrease 
the nepheline content. In light of these results, hypothesis (ii) seems the most plausible possibility (Scheme 2).

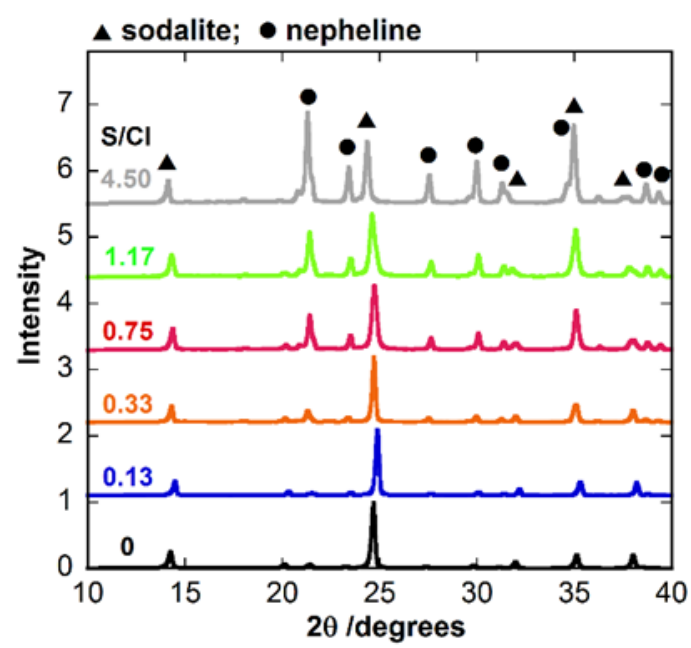

Fig. 5. XRD patterns of samples with different nominal sulphur/chloride $(\mathrm{S} / \mathrm{Cl})$ ratios, normalized to the sodalite peak at $\approx 24.8^{\circ}$, in which sodalite $(\boldsymbol{\Delta})$ and nepheline crystalline phases $(\bullet)$ are observed.

Several authors refer to the importance of $\mathrm{NaCl}$ in the synthesis of the sodalite structure from zeolite Na-LTA, ${ }^{38,40}$ however other inorganic compounds such as $\mathrm{Na}_{2} \mathrm{SO}_{4}$ and $\mathrm{Na}_{2} \mathrm{SeO}_{3}$ can be used to produce sodalites with other anions trapped in their cages. ${ }^{27,28}$ The sodalite zeolite formation is relatively sensitive to the reaction conditions and to the anions and cations used during the synthesis protocols, ${ }^{38,43}$ and there are also multiple conditions that can influence the transformation of this zeolite topology to another. ${ }^{44}$ Therefore the nepheline phase formation may be favoured when the synthesis is carried out with low chloride and high sulphur contents.

The nepheline/sodalite phase intensity ratios, obtained from the XRD patterns, increased significantly for the samples with $\mathrm{S} / \mathrm{Cl}>0.21$ (see Table 1). From the XRD patterns, it is possible to calculate the lattice parameters from the crystalline sodalite and nepheline structure using Bragg's Law, considering that sodalite and nepheline form cubic and 
hexagonal structures, respectively. While the sodalite phase presents lattice parameters ca. $\mathrm{a}=8.85 \AA$, the nepheline displays $\mathrm{a}=9.85 \AA$ and $\mathrm{c}=8.32 \AA$ (Table 1 ), which once more are in agreement with values reported in the literature. ${ }^{33,45}$

Moreover, the sodalite unit cell has a small volume increase with respect to the sulphur content (Table 1). This can be an indication of the confinement of sulphur within the sodalite cages in the form of $\mathrm{S}_{2}^{-}$, which has a slightly larger ionic radius than $\mathrm{Cl}^{-}(1.84$ and $1.81 \AA$, respectively), or as polysulphide clusters. No significant volume changes are observed for the nepheline unit cell throughout the different sulphur loadings. These data suggest that the entrapment of sulphur and/or chloride anions occurs predominantly in the crystalline phase of the sodalite and not in the nepheline.

Table 1. Unit cell lattice parameters ( $a, b$ and $c)$ and volume $(V)$ for sodalite and nepheline phases formed in the different samples with nominal molar ratios of $\mathrm{S} / \mathrm{Cl}=0,0.06,0.13$, $0.21,0.33,0.50,0.75,1.17,2.0$ and 4.5 . Nepheline/ sodalite relative ratio obtained from the XRD data. ${ }^{\text {a }}$

\begin{tabular}{|c|c|c|c|c|c|c|}
\hline \multirow{2}{*}{$\begin{array}{c}\text { Sample } \\
\text { S/Cl= }\end{array}$} & \multicolumn{2}{|c|}{ Sodalite } & \multicolumn{3}{|c|}{ nepheline } & \multirow{2}{*}{$\begin{array}{c}\text { nepheline/ } \\
\text { sodalite }^{\mathrm{a}}\end{array}$} \\
\hline & $\begin{array}{c}\mathbf{a}=\mathbf{b}=\mathbf{c} \\
\operatorname{axis}(\AA)\end{array}$ & $\mathbf{V}\left(\AA^{3}\right)$ & $\begin{array}{c}\mathbf{a}=\mathbf{b} \\
\text { axis ( }(\AA)\end{array}$ & c axis $(\AA)$ & $\mathbf{V}\left(\AA^{3}\right)$ & \\
\hline 0 & $8.82 \pm 0.04$ & $685.5 \pm 0.1$ & $9.95 \pm 0.04$ & $8.29 \pm 0.04$ & $821.0 \pm 0.1$ & 0.142 \\
\hline 0.06 & $8.78 \pm 0.06$ & $677.3 \pm 0.2$ & $9.87 \pm 0.02$ & $8.31 \pm 0.04$ & $810.3 \pm 0.1$ & 0.153 \\
\hline 0.13 & $8.73 \pm 0.08$ & $666.6 \pm 0.2$ & $9.83 \pm 0.03$ & $8.25 \pm 0.04$ & $797.7 \pm 0.1$ & 0.165 \\
\hline 0.21 & $8.79 \pm 0.06$ & $679.5 \pm 0.2$ & $9.84 \pm 0.02$ & $8.34 \pm 0.04$ & $807.5 \pm 0.1$ & 0.172 \\
\hline 0.33 & $8.80 \pm 0.05$ & $681.6 \pm 0.1$ & $9.86 \pm 0.01$ & $8.34 \pm 0.04$ & $810.5 \pm 0.1$ & 0.229 \\
\hline 0.50 & $8.84 \pm 0.03$ & $690.5 \pm 0.1$ & $9.88 \pm 0.01$ & $8.37 \pm 0.04$ & $816.5 \pm 0.1$ & 0.274 \\
\hline 0.75 & $8.81 \pm 0.10$ & $683.5 \pm 0.3$ & $9.82 \pm 0.01$ & $8.30 \pm 0.04$ & $800.1 \pm 0.1$ & 0.372 \\
\hline 1.17 & $8.83 \pm 0.08$ & $687.8 \pm 0.2$ & $9.82 \pm 0.01$ & $8.30 \pm 0.04$ & $800.1 \pm 0.1$ & 0.453 \\
\hline 2.0 & $8.89 \pm 0.04$ & $702.9 \pm 0.1$ & $9.84 \pm 0.02$ & $8.34 \pm 0.04$ & $807.2 \pm 0.1$ & 0.691 \\
\hline 4.5 & $8.90 \pm 0.04$ & $715.1 \pm 0.1$ & $9.84 \pm 0.01$ & $8.34 \pm 0.04$ & $806.6 \pm 0.1$ & 0.861 \\
\hline
\end{tabular}

${ }^{a}$ The nepheline/sodalite relative ratio was calculated by dividing, in each sample, the area of the peak at ca. $2 \theta=30.00^{\circ}$ of nepheline, by the area of the peak at $c a \cdot 2 \theta=24.60^{\circ}$, from sodalite

In agreement with this hypothesis, $\mu$-EDXRF experiments showed that the peak corresponding to sulphur at $2.3 \mathrm{keV}$ increases with the $\mathrm{S} / \mathrm{Cl}$ molar ratio until 1.17 , and 
then abruptly decreases, see Fig. 6. Raman microspectroscopy showed that all samples are relatively heterogeneous and a structural modification with the increase of sulphur concentration was observed, which is in agreement with the abovementioned XRD results

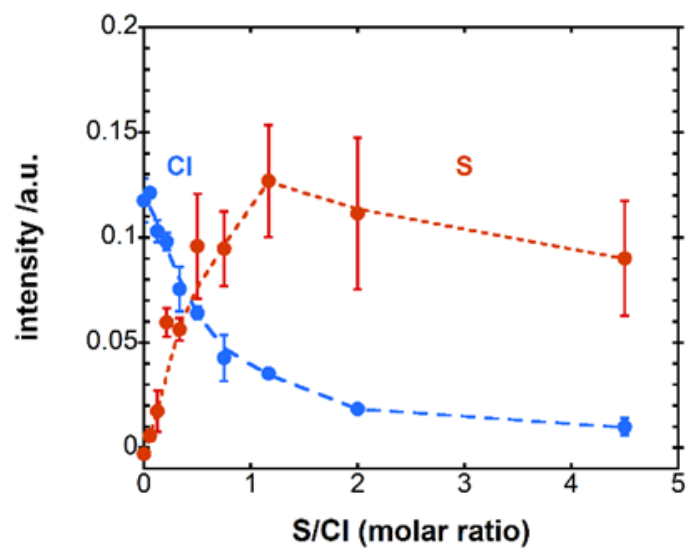

Fig. 6. $\mu$-EDXRF analysis of photoluminescent sulphur-zeolites corresponding to a nominal molar ratio of $\mathrm{S} / \mathrm{Cl}=0.06,0.13,0.21,0.33,0.50,0.75,1.17,2.0$ and 4.5. Area of the peak at 2.6 $\mathrm{keV}$ of $\mathrm{K} \alpha \mathrm{Cl}$ (blue dots) and area of the peak at $2.3 \mathrm{keV}$ of $\mathrm{K} \alpha \mathrm{S}$ (orange dots).

The Raman spectra of samples with low sulphur content exhibit the usual features of sodalite topology: (i) two bands between 250 and $300 \mathrm{~cm}^{-1}$ and a more intense band around $465 \mathrm{~cm}^{-1}$ that correspond to $\mathrm{T}-\mathrm{O}-\mathrm{T}$ ring vibrations $(\mathrm{T}=\mathrm{Si}, \mathrm{Al})$, and the band between 950 and $1050 \mathrm{~cm}^{-1}$ is consistent with $\mathrm{Si}-\mathrm{O}$ bond stretching vibrations. ${ }^{46}$ These vibrational modes are also visible on the Raman spectra of the samples with $\mathrm{S} / \mathrm{Cl}>0.21$, for instance in sample $\mathrm{S} / \mathrm{Cl}=1.17$ (Fig. 7), however these also display typical features of nepheline crystalline phases, namely bands at 403,428 and $468 \mathrm{~cm}^{-1}$ consistent with stretching vibration modes of T-O-T from the ring structures. ${ }^{47}$ This vibrational information of $\mathrm{T}-\mathrm{O}-\mathrm{T}$ and $\mathrm{Si}-\mathrm{O}$ bonds is consistent with the increase of the nepheline/sodalite phase intensity ratios for higher sulphur concentrations, pointing out to more entrapped sulphur anions in the remaining sodalite structure until $\mathrm{S} / \mathrm{Cl}=1.17$. 


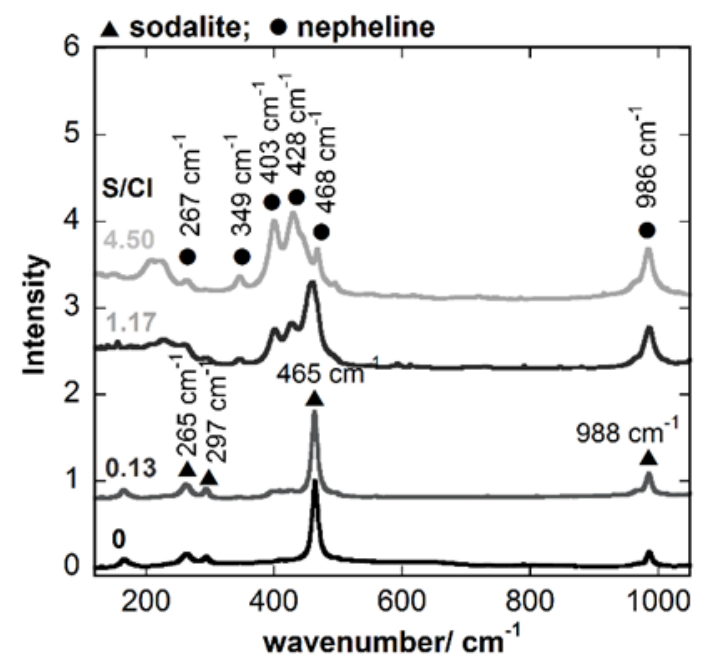

Fig. 7. Raman spectra of samples with different nominal sulphur/chloride $(\mathrm{S} / \mathrm{Cl})$ ratios normalized at the maximum intensity, in which sodalite $(\boldsymbol{\bullet})$ and nepheline crystalline phases $(\bullet)$ are observed.

The structural analysis for $\mathrm{S} / \mathrm{Cl}$ molar ratios below 0.5 shows samples with a mostly pure sodalite crystalline phase, with entrapped $\mathrm{S}_{2}{ }^{-}$species inside the cavities. These species are responsible for the orange photoluminescence displayed by the samples. For higher S/Cl molar ratios, a nepheline crystalline phase formation is favoured due to higher sulphur contents. As it was already mentioned, anions are left out from the nepheline cavities in rich sulphur samples, ${ }^{33,40,41}$ which corresponds to a situation where the overall sulphur and chlorine intercalation of the sample decreases (see Fig. 6). Nevertheless, for the samples with higher $\mathrm{S} / \mathrm{Cl}$ ratios, in the remaining sodalite structural cavities, a higher local sulphur concentration is expected, since the sulphur concentration increases and the amount of cavities that can confine these anions decrease. As a result a volume increase of the remaining sodalite cage occurs and polysulphide clusters appear (tentatively assigned to $\mathrm{S}_{4}^{2-}$ ) displaying a red shifted structureless emission.

\subsection{Photoluminescence quantum efficiency and temperature stability}


External quantum efficiencies (EQEs) were measured at two different excitation wavelengths, $385 \mathrm{~nm}$ and $345 \mathrm{~nm}$, which are the excitation maxima of the orange and red/NIR emitting species, respectively. With $385 \mathrm{~nm}$ excitation an optimized EQE of 53\% was obtained when $\mathrm{S} / \mathrm{Cl}=0.13$, indicating a rather high light conversion efficiency, see Fig. 8 and Table SI-1 in the supplementary information. This value decreases with increasing the $\mathrm{S} / \mathrm{Cl}$ nominal molar ratios, reaching a value below $10 \%$ at $\mathrm{S} / \mathrm{Cl}=4.5$. This effect can be probably due to a self-quenching effect caused by Poisson distribution of sulphur clusters within the matrix, where the increase of sulphur content leads to the annihilation of excited-state species of $\mathrm{S}_{2}-{ }^{48,49} \mathrm{EQE}$ values obtained in samples having $\mathrm{S} / \mathrm{Cl}<1.17$, measured at $345 \mathrm{~nm}$ excitation; display the same qualitative trend as that when $385 \mathrm{~nm}$ was used as excitation wavelength. Excitation at $345 \mathrm{~nm}$ is the optimal wavelength to excite red/NIR emitting species; however, it can also excite the orange emitting centres, giving rise to the observed EQE trend.

For values higher than $\mathrm{S} / \mathrm{Cl}=1.17$ an $\mathrm{EQE}$ of about $10 \%$ is measured for the red/NIR emitting species, when excited at $345 \mathrm{~nm}$, which seems independent of the sulphur concentration.

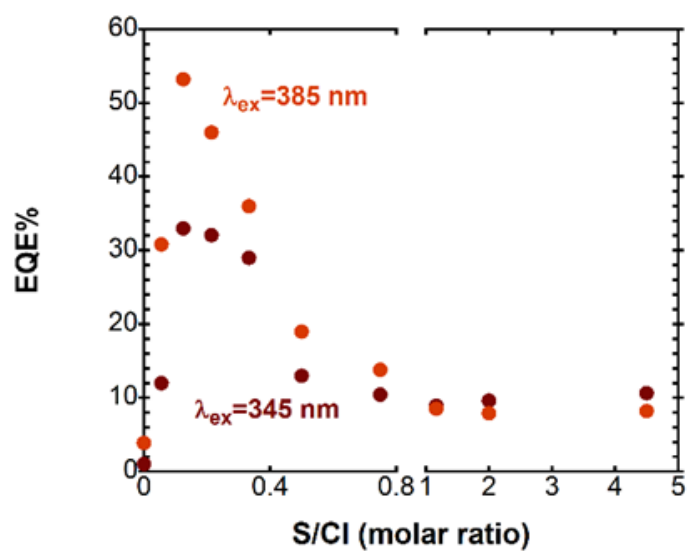

Fig. 8. External Quantum Efficiency of photoluminescent sulphur-zeolites corresponding to a nominal molar ratio of $\mathrm{S} / \mathrm{Cl}=0,0.06,0.13,0.21,0.33,0.50,0.75,1.17,2.0$ and $4.5, \lambda_{\mathrm{ex}}=345$ and $385 \mathrm{~nm}$. Photons were collected between 440 and $850 \mathrm{~nm}$. 
The synthesis optimization allows the selection of optimal conditions to obtain materials with maximum photoluminescence brightness. This is achieved for the sample having $\mathrm{S} / \mathrm{Cl}=0.33$, where an optimal combination of light absorption and $\mathrm{EQE}$ is observed, see Table SI-1 (ESI). Technological applications of these materials may imply their use at high temperatures; therefore their photoluminescence was recorded at different temperatures up to $450{ }^{\circ} \mathrm{C}$. Indeed for sample $\mathrm{S} / \mathrm{Cl}=0.21$ a strong emission intensity is still observed even at $450{ }^{\circ} \mathrm{C}$, with a decrease of overall intensity to about $70 \%$ of its initial value (see Fig. 9). A broadening of the characteristic vibrational bands is observed, but it is not significant enough to render observable thermochromic effects in terms of colour space.
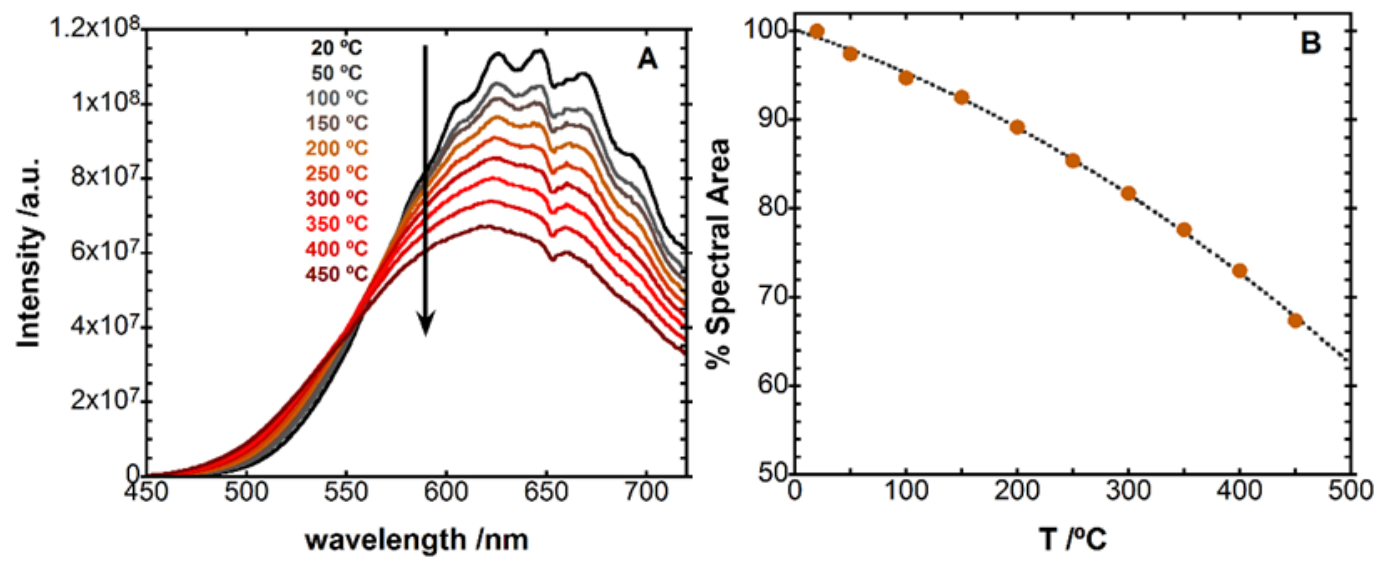

Fig. 9. (A) Photoluminescence spectra of sample $\mathrm{S} / \mathrm{Cl}=0.21$ at different temperatures, $\lambda_{\mathrm{exc}}=385$ $\mathrm{nm}$, detection range $450-750 \mathrm{~nm}$. (B) Percentage of the integrated spectral area of the emission spectra from (A) at several temperatures for sample $\mathrm{S} / \mathrm{Cl}=0.21$, where the emission spectra at room temperature corresponds to $100 \%$.

It is observed that highly luminescent and thermal-stable sulphur-zeolites displaying EQE's of up to $53 \%$, when excited between 300 to $450 \mathrm{~nm}$, can be synthesized. Due to these peculiar properties, such materials are strongly appealing to be employed in optoelectronic applications. 


\section{CONCLUSIONS}

This study provides the development of stable photoluminescent sulphur-zeolite materials containing sulphide clusters as the emissive centres, with interesting emissive properties such as high EQE values (up to 53\%), large Stokes shifts and high temperature stability up to $450{ }^{\circ} \mathrm{C}$.

The produced S-zeolite samples with $\mathrm{S} / \mathrm{Cl}$ nominal molar ratios up to 0.33 display a broad emission band with a very well defined vibronic structure and maximum intensity at around $650 \mathrm{~nm}$ when excited at $385 \mathrm{~nm}$, fully consistent with sodalite intercalated $\mathrm{S}_{2}{ }^{-}$ clusters. For higher sulphur concentrations, a conversion to an emission band centered at $780 \mathrm{~nm}$ is observed at the expense of the orange emissive species, which is most likely due to the formation of other polysulfide species. Structural characterization reveals the formation of two different crystalline phases derived from the starting LTA zeolite, namely sodalite and nepheline, when low and high sulphur loadings were employed, respectively.

Besides their good physicochemical properties, the developed photoluminescent S-zeolite materials were produced using a cost-effective process where inexpensive raw materials were employed. Therefore, these materials can be very interesting for light downconversion applications such as phosphors in lighting devices, for instance, in commercial white light emitting LEDs whose excitation source falls within the excitable spectral range of luminescent S-zeolites. Further research is ongoing to develop alternative synthetic strategies to study other species as emissive centers, such as other chalcogens precursors, which may extend the applicability of photoluminescent chalcogen-zeolites. 


\section{SUPPORTING INFORMATION DESCRIPTION}

Photochromic sample preparation procedure; diffuse reflectance spectra of S-zeolites; images of samples with $\mathrm{S} / \mathrm{Cl}=0.0,0.06$ and 0.13 , photoluminescence spectrum fitted with the sum of Gaussian functions, two dimensional excitation-emission profiles of photoluminescent S-zeolites; fluorescence microscopy images of S-zeolites; extra XRD patterns, and EQE’s of S-zeolites.

\section{ACKNOWLEDGMENTS}

EC (project NMP4-SL2012-310651 under FP7-NMP-2012-SMALL-6) and Portuguese FCT-MCTES (PTDC/QEQ-QIN/3007/2014, UID/EAT/00729/2013 and UID/QUI/50006/2013) co-financed by the ERDF under the PT2020 Partnership Agreement (POCI-01-0145-FEDER -007265) are acknowledged for financial support. The authors would like to thank the Radiation, Elements and Isotopes group from the Centro de Ciências e Tecnologias Nucleares for allowing the use of their ball mill equipment. E. Coutino-Gonzalez gratefully acknowledges the support provided by Cátedras CONACYT. M.B.J. Roeffaers acknowledge financial support from the Research Foundation-Flanders (FWO, grant G.0B39.15 and AKUL/15/15 - G0H0816N) and the KU Leuven Research Fund (C14/15/053). 


\section{REFERENCES}

1 Sastri, V. S.; Bünzli, J. C. G.; Ramachandra Rao, V.; Rayudu, G. V. S.; Perumareddi, J. R. Modern Aspects of Rare Earths and their Complexes; Elsevier, Amsterdam, 2003.

2 Bünzli, J. C. G.; Comby, S.; Chauvin, A. S.; Vandevyver, C. D. B. New Opportunities for Lanthanide Luminescence. J. Rare Earths 2007, 25 (3), 257-274.

3 Singh, S. K.; Singh, A. K.; Rai, S. B. Efficient Dual Mode Multicolor Luminescence in a Lanthanide Doped Hybrid Nanostructure: a Multifunctional Material. Nanotechnology 2011, 22, 275703.

4 Ke, L.; Chua, S. J.; Zhang, K.; Yakovlev, N. Degradation and Failure of Organic LightEmitting Devices. Appl. Phys. Lett. 2002, 80, 2195-2197.

5 Kondakov, D. Y.; Lenhart, W. C.; Nichols, W. F. Operational Degradation of Organic Light-Emitting Diodes: Mechanism and Identification of Chemical Products. J. Appl. Phys. 2007, 101, 024512.

6 Xie, R. J.; Hirosaki, N. Silicon-based Oxynitride and Nitride Phosphors for White LEDs-A Review. Sci. Tech. Adv. Mater. 2007, 8, 588-600.

7 Ye, S.; Xiao, F.; Pan, Y. X.; Ma, Y. Y.; Zhang, Q. Y. Phosphors in Phosphor-converted White Light-Emitting Diodes: Recent Advances in Materials, Techniques and Properties. Mater. Sci. Eng. R. Rep. 2010, 71, 1-34.

8 Nguyen, H. P. T.; Cui, K.; Zhang, S.; Djavid, M.; Korinek, A.; Botton G.A.; Mi, Z. Controlling Electron Overflow in Phosphor-Free InGaN/GaN Nanowire White LightEmitting Diodes. Nano Lett. 2012, 12 (3), 1317-1323.

9 Robson, K. C. D.; Bomben, P. G.; Berlinguette, C. P. Cycloruthenated Sensitizers: Improving the Dye-sensitized Solar Cell with Classical Inorganic Chemistry Principles. Dalton Trans., 2012, 41, 7814-7829.

10 Chang, Y. L.; Song, Wang, Y. Z.; Helander, Qiu, M. G. J.; Chai, L.; Liu, Z.; Scholes, G. D.; Lu, Z. Highly Efficient Warm White Organic Light-Emitting Diodes by Triplet Exciton Conversion. Adv. Funct. Mater. 2013, 23, 705-712.

11 Maas, H.; Currao A.; Calzaferri, G. Encapsulated Lanthanides as Luminescent Materials. Angew. Chem. Int. Ed. 2002, 41, 2495-2497.

12 Diez, I.; Rãs, R. H. A. Fluorescent Silver Nanoclusters, Nanoscale, 2011, 3, 1963-1970.

13 Choi, S.; Dickson, R. M.; Yu, J. Developing Luminescent Silver Nanodots for Biological Applications. Chem. Soc. Rev., 2012, 41 (5), 1867-1891.

14 Cremer, G. De; Coutino-Gonzalez, E.; Roeffaers, M. B. J.; Moens, B.; Ollevier, J.; Auweraer, M.; Schoonheydt, R.; Jacobs, P. A.; Schryver, F. C. De; Hofkens, J. Characterization of Fluorescence in Heat-Treated Silver-Exchanged Zeolites. J. Am. Chem. Soc. 2009, 131 (8), 3049-3056. 
15 He, J.; Ba, Y.; Ratcliffe, C. I.; Ripmeester, J. A.; Klug, D. D.; Tse, J. S.; Preston, K. F. Encapsulation of Silicon Nanoclusters in Zeolite Y. J. Am. Chem. Soc. 1998, 120 (41), 10697-10705.

16 Fenwick, O.; Coutiño-Gonzalez, E.; Grandjean, D.; Baekelant, W.; Richard, F.; Bonacchi, S.; De Vos, D.; Lievens, P.; Roeffaers, M. B. J.; Hofkens, J.; Samorì, P. Tuning the Energetics and Tailoring the Optical Properties of Silver Clusters Confined in Zeolites. Nat. Mater. 2016, 15, 1017-1022.

17 Coutino-Gonzalez, E. ; Roeffaers, M. B. J. ; Dieu, B. ; De Cremer, G. ; Leyre, S. ; Hanselaer, P.; Fyen, W.; Sels, B. ; Hofkens, J. Determination and Optimization of the Luminescence External Quantum Efficiency of Silver-Clusters Zeolite Composites. $J$. Phys. Chem. C 2013, 117 (14), 6998-7004.

18 Dedecek, J.; Sobalik, Z.; Tvaruazkova, Z.; Kaucky D.; Wichterlova, B. Coordination of $\mathrm{Cu}$ Ions in High-Silica Zeolite Matrixes. $\mathrm{Cu}^{+}$Photoluminescence. IR of NO Adsorbed on $\mathrm{Cu}^{2+}$, and $\mathrm{Cu}^{2+}$ ESR Study, J. Phys. Chem. 1995, 99 (44), 16327-16337.

19 Sun, H. T.; Matsushita, Y.; Sakka, Y.; Shirahata, N.; Tanaka, M.; Katsuya, Y.; Gao, H.; Kobayashi, K. Synchrotron X-ray, Photoluminescence, and Quantum Chemistry Studies of Bismuth-Embedded Dehydrated Zeolite Y. J. Am. Chem. Soc. 2012, 134 (6), 2918-2921.

${ }^{20}$ Leiggener, C.; Calzaferri, G. Synthesis and Luminescence Properties of $\mathrm{Ag}_{2} \mathrm{~S}$ and $\mathrm{PbS}$ Clusters in Zeolite A. Chem Eur. J., 2005, 11, 7191-7198.

${ }^{21}$ Williams, E. R.; Simmonds, A.; Armstrong, J. A.; Weller, M. T. Compositional and Structural Control of Tenebrescence. J. Mater. Chem., 2010, 20, 10883-10887.

22 Kirk, R.D. The Luminescence and Tenebrescence of Natural and Synthetic Sodalite. Am. Miner., 1955, 40, 22-31.

${ }^{23}$ Clark, R. J. H.; Dines, T. J.; Kurmoo, M. On the Nature of the Sulfur Chromophores in Ultramarine Blue, Green, Violet, and Pink and of the Selenium Chromophore in Ultramarine Selenium: Characterization of Radical Anions by Electronic and Resonance Raman Spectroscopy and the Determination of Their Excited-State Geometries. Inorg. Chem., 1983, 22, 2766-2772.

${ }^{24}$ Sidike, A.; Sawuit, A.; Wang, X.; Zhu, H.; Kobayashi, S.; Kusachi, I. Fine Structure in photoluminescence spectrum of $\mathrm{S}_{2}{ }^{-}$center in sodalite. Phys. Chem. Miner. 2007, 34, 477484.

25 Buxbaum, G. Industrial Inorganic pigments, $2^{\text {nd }}$ ed., Wiley VCH, Weinheim, 1998.

26 Warner, T. E.; Hutzen Andersen J. The Effects of Sulfur Intercalation on the Optical Properties of Artificial 'Hackmanite', $\mathrm{Na}_{8}\left[\mathrm{Al}_{6} \mathrm{Si}_{6} \mathrm{O}_{24}\right] \mathrm{Cl}_{1.8} \mathrm{~S}_{0.1}$; 'Sulfosodalite', $\mathrm{Na}_{8}\left[\mathrm{Al}_{6} \mathrm{Si}_{6} \mathrm{O}_{24}\right] \mathrm{S}$; and Natural Tugtupite, $\mathrm{Na}_{8}\left[\mathrm{Be}_{2} \mathrm{Al}_{2} \mathrm{Si}_{8} \mathrm{O}_{24}\right](\mathrm{Cl}, \mathrm{S})_{2-\delta}$. Phys. Chem. Minerals 2012, 39, 163-168. 
27 Reinen, D.; Lindner, G. G. The Nature of the Chalcogen Colour Centres in UltramarineType Solids. Chem. Soc. Rev. 1999, 28, 75-84.

28 Norrbo, I.; Gluchowski, P.; Paturi, P.; Sinkkonen, J.; Lastusaari, M. Persistent Luminescence of Tenebrescent $\mathrm{Na}_{8} \mathrm{Al}_{6} \mathrm{Si}_{6} \mathrm{O}_{24}(\mathrm{Cl}, \mathrm{S})_{2}$ : Multifunctional Optical Markers. Inorg. Chem. 2015, 54, 7717-7724.

29 Mirabella, F. M. Modern Techniques in Applied Molecular Spectroscopy, 1998, John Wiley and Sons, New York.

30 Giggenbach, W. Optical Spectra and Equilibrium Distribution of Polysulfide Ions in Aqueous Solution at 20.deg. Inorg.Chem. 1972, 11 (6), 1201-1207.

31 Gaft, M.; Panczer, G.; Nagli, L.; Yates, H. Laser-induced Time Resolved Luminescence of Tugtupite, Sodalite and Hackmanite. Phys. Chem. Miner. 2009, 36, 127-141.

32 Weller, M. T. J. Where Zeolites and Oxides Merge: Semi-condensed Tetrahedral Frameworks. Chem. Soc., Dalton Trans., 2000, 4227-4240.

33 Lambregts, M. J.; Frank, S. M. Powder XRD, SEM, and Multinuclear MAS-NMR Investigations of the Interactions Between Glass and Crystalline Phases of $\mathrm{Li}, \mathrm{Na}$, or $\mathrm{K}$ Ceramic Waste Forms. J. Am. Ceram. Soc., 2005, 88, 2255-2261.

${ }^{34}$ Chang, I. F. Synthesis of Photochromic and Cathodochromic Sodalite. J. Electrochem. Soc. 1974, 121, 815-820.

35 Subotić, B.; Sekovanić, L. Transformation of Zeolite A into Hydroxysodalite: II. Growth Kinetics of Hydroxysodalite Microcrystals. J. Cryst. Growth 1986, 75, 561-572.

36 Walton, R. I.; Millange, F.; O'Hare, D. An in Situ Energy-Dispersive X-ray Diffraction Study of the Hydrothermal Crystallization of Zeolite A. 1. Influence of Reaction Conditions and Transformation into Sodalite. J. Phys. Chem. B 2001, 105 (1), 83-90.

37 Greer, H.; Wheatley, P. S.; Ashbrook, S. E.; Morris, R. E.; Zhou, W. Early Stage Reversed Crystal Growth of Zeolite A and Its Phase Transformation to Sodalite. J. Am. Chem. Soc. 2009, 131 (49), 17986-17992.

38 Ding, L.; Yang, H.; Rahimi, P.; Omotoso, O.; Friesen, W.; Fairbridge, C.; Shi, Y.; Ng, S. Solid Transformation of Zeolite NaA to Sodalite. Micropor. Mesopor. Mat. 2010, 130, 303-308.

39 Markovic, S.; Dondur, V.; Dimitrijevic, R. FTIR Spectroscopy of Framework Aluminosilicate Structures: Carnegieite and Pure Sodium Nepheline J. Mol. Struct. 2003, 654, 223-234.

40 Finch, A. A. Conversion of Nepheline to Sodalite during Subsolidus Processes in Alkaline Rocks. Mineral. Mag., 1991, 55, 459-463.

${ }^{41}$ Sharp, Z. D.; Helfrich, G. R.; Bohlen, S. R.; Essene, E. J. The Stability of Sodalite in the System $\mathrm{NaAlSiO}_{4}-\mathrm{NaCl}$. Geochim. Cosmochim. Acta, 1989, 53, 1943-1954. 
42 Ohgushi, T.; Ishimaru, K. Nepheline and Carnegieite Ceramics from A-Type Zeolites by Microwave Heating. J. Am. Ceram. Soc. 2001, 84, 321-27.

43 Stormer Jr., J. C; Carmichael, I. S. E. The Free Energy of Sodalite and the Behavior of Chloride, Fluoride and Sulfate in Silicate Magmas. Am. Mineral. 1971, 56, 292-306.

44 Ocanto, F.; Álvarez, R.; Urbina de Navarro, C.; Lieb, A.; Linares, C. F. Influence of the Alkalinity and $\mathrm{NO}_{3}{ }^{-} / \mathrm{Cl}^{-}$Anionic Composition on the Synthesis of the Cancrinite-Sodalite System. Micropor. Mesopor. Mat. 2008, 116, 318-322.

45 Henderson, C. M. B.; Taylor, D. The Thermal Expansion of Synthetic AluminosilicateSodalites, $\mathrm{M}_{8}\left(\mathrm{Al}_{6} \mathrm{Si}_{6} \mathrm{O}_{24}\right) \mathrm{X}_{2}$. Phys. Chem. Minerals 1978, 2, 337-347.

46 Creighton, J. A.; Deckman, H.W.; Newsam, J.M. Computer Simulation and Interpretation of the Infrared and Raman Spectra of Sodalite Frameworks. J. Phys. Chem. 1994 (2), 98, $448-459$.

47 Matson, D. W.; Sharma, S. K.; Philpotts, J. A. Raman Spectra of some Tectosilicates and of Glasses Along the Orthoclase-Anorthite and Nepheline-Anorthite Joins. Am. Mineral. 1986, 71, 694-704.

48 Boens, N.; Van der Auweraer, M. Identifiability of Models for Fluorescence Quenching in Aqueous Micellar Systems ChemPhysChem. 2005, 6 (11), 2352-2358.

49 Hashimoto, S. Optical Spectroscopy and Microscopy Studies on the Spatial Distribution and Reaction Dynamics in Zeolites. J. Phys. Chem. Lett. 2011, 2 (5), 509-519. 
TOC Graphic:

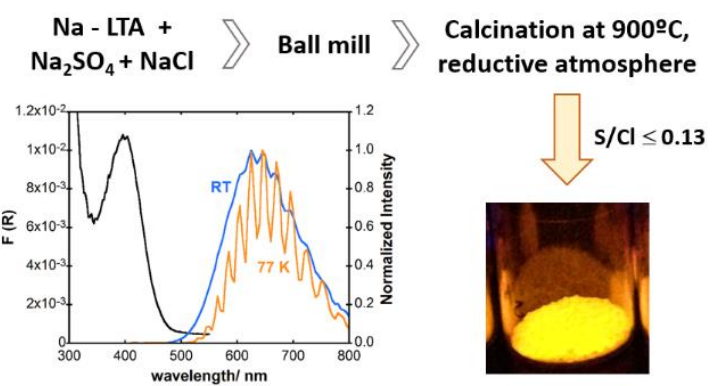

Development of stable photoluminescent sulphur-zeolite materials 